\title{
TEXTUALIDADES CONTEMPORÂNEAS: HIBRIDISMO E EXÍLIO EM $O$ ROMANCE DA MINHA VIDA, DE LEONARDO PADURA
}

\author{
Amanda Pérez Montañés (LEM/UEL) \\ amandapm34@hotmail.com
}

\section{RESUMO}

O presente trabalho tem por objetivo analisar as especificidades textuais em $O$ romance da minha vida (2002), do escritor cubano Leonardo Padura. A obra caracteriza-se pela mistura de fatos reais com ficção presentes em diversos registros discursivos (romance, biografia, autobiografia, memórias) e a superposição de temporalidades e espacialidades, características que evidenciam, a partir do hibridismo textual, novas tendências da narrativa latino-americana contemporânea, ressaltando a transposição dos limites entre o ficcional e o documental. Depois de dezoito anos de exílio, Fernando Terry decide voltar à Havana, com a esperança de encontrar finalmente a autobiografia desaparecida do poeta romântico José María Hereida (que tem por título, precisamente, "O romance da minha vida"), objeto de estudo de sua tese de doutorado; também quer esclarecer quem o denunciou e provocou sua expulsão da universidade forçando-o ao exílio. Nesse primeiro plano temporal sobrepõe-se a biografia de Heredia no começo do século XIX quando Cuba pertencia ao domínio espanhol. Um terceiro plano surge na história: a narração dos últimos dias de José de Jesús de Heredia, fillho do poeta, que transcorrem a inícios do século XX. Dessa forma, Padura compõe seu romance num jogo de perspectivas históricas e diversas textualidades produzindo efeitos de realidade na fícção.

Palavras-chave: Hibridismo; Exílio; Leonardo Padura.

A partir dos anos 1990 começam a produzir-se na literatura da América Latina uma série de rupturas que modificam profundamente a sua estrutura e funcionamento, e em consequência, as formas de expressão dessa literatura que já não respondem mais às tendências da tradição anterior. Rupturas que resultam de um duplo processo: de um lado, concernem às modalidades da escrita, e de outro, correspondem ao desenvolvimento da teoria literária dentro e fora dela. Dessa forma, na narrativa latinoamericana contemporânea, o realismo mágico de Gabriel García Márquez, o fantástico borgiano ou o onírico de Juan Rulfo, já ficaram atrás enquanto modelos a serem seguidos pelos narradores atuais. Agora, trata-se de pensar, entre outras possibilidades, a literatura latino-americana contemporânea a partir do conceito de fronteira, eixo articulador de proposições em torno a entrecruzamentos e/ou deslocamentos formais, genéricos e temáticos, cuja reflexão deve estar marcada pela "contemporaneidade" das novas tendências e estilos, e as possibilidades de reconfiguração das tendências passadas como forma de inovação útil para pensar novas formas de expressão e representação.

A inovação, elemento central da literatura latino-americana contemporânea, leva a superar as fronteiras artificiais dos gêneros literários produzindo obras que não se deixam circunscrever com facilidade em definições fechadas de gênero, forçando a 


\section{SEMINÁRIO DE PESQUISA EM CIÊNCIAS HUMANAS - SEPECH \\ Humanidades, Estado e desafios didático-científicos \\ Londrina, 27 a 29 de julho de 2016}

criação de categorias alternativas para defini-la: romance-documental, autoficção, biografia-ensaio, textos híbridos, entre outras formas, que parecem querer sair de seus próprios limites além das margens da literatura. Como afirma Ana Cecilia Olmos (2011), trata-se de escrituras que:

[...] impulsionam a literatura em direção de uma deriva estética que desestabiliza as convenções, não para propor outras formas que acabem igualmente esclerosadas na proteção de seus limites, senão para levar a literatura para além do limite, empurrá-la permanentemente para o abismo que se abre quando se renuncia à tranquilidade das linguagens ordenadas e as certezas de seus fundamentos (apud GUTÍERREZ, 2015, p. 95).

Nas novas derivas estéticas, "[...] a mistura de gêneros ficcionais e documentais, a inclusão de documentos e imagens de arquivo, o jogo permanente com a identidade real do autor, são algumas das estratégias usadas pelos textos para produzir estes efeitos de realidade" (GUTIÉRREZ, 2015, p. 96), aproveitando recursos do ensaio e da autobiografia que fazem um uso literário do discurso histórico e do discurso da crítica literária. Dessa forma, as formas híbridas buscam evidenciar marcas do real para desestabilizar o estatuto ficcional da narrativa. Exemplo desse tipo de efeito discursivo pode ser encontrado em $O$ romance da minha vida (2002), do escritor cubano Leonardo Padura (1955), cuja obra se caracteriza pela mistura de fatos reais e ficcionais expressados em diversos registros literários que convivem numa mesma obra: romance, biografia, autobiografia, memórias ficcionais.

A superposição de temporalidades e espacialidades é outra das características que evidenciam, a partir do hibridismo textual, a inovação na narrativa de Leonardo Padura, ressaltando assim a transposição dos limites entre o ficcional e o documental. Nesse sentido, a obra se define pela articulação de fragmentos de histórias pertencentes a diversas épocas e as vivências dos personagens que as habitam numa exaltação de afetos, emoções, delações, traições, conspirações, exílios. Ao contar a História de Cuba pela voz de três de seus personagens principais, desde diversas perspectivas, Padura também questiona os limites do romance como gênero, colocando no centro da narrativa a problematização do conceito de ficção.

Mas, o que faz em $O$ romance da minha vida com que a ficção, sem ser verdade, seja verdadeira? Pergunta central para entender a trama do romance, tecida, como já dito, na justaposição de três vozes narrativas articuladas num jogo de perspectivas históricas e diversas textualidades, tendo como eixo principal a autobiografia de José María Hereida, poeta romântico cubano, sobre a qual gira o enredo da história. Esse recurso narrativo produz efeitos de realidade na ficção, ou como afirma Padura (2003): "A existência real do poeta e dos personagens que o rodeiam, [...] tem sido posta em função de um discurso fictício onde as peripécias reais e ficcionais se entrecruzam livremente" (apud BEHAR, 2007, p. 23) [tradução minha].

\footnotetext{
1 "La existencia real del poeta, y de los personajes que lo rodearon, [...] ha sido puesta en función de un discurso ficticio en el que las peripecias reales y las novelescas se entrecruzan libremente" (PADURA apud BEHAR, 2007, p. 23).
} 


\section{SEMINÁRIO DE PESQUISA EM CIÊNCIAS HUMANAS - SEPECH \\ Humanidades, Estado e desafios didático-científicos \\ Londrina, 27 a 29 de julho de 2016}

O romance de minha vida se divide em três partes: "O mar e os regressos", "Os desterros", "Noticia Histórica", e em cada uma dessas partes operam três níveis narrativos que articulam as histórias do romance, começando com a narração, em terceira pessoa, da vida do intelectual cubano Fernando Terry, nas últimas décadas do século XX, quem depois de dezoito anos de exílio na Espanha decide voltar à Havana com a esperança de encontrar finalmente a autobiografia desaparecida de José María Hereida (que tem por título, precisamente, "O romance da minha vida"), objeto de estudo de sua tese de doutorado. Também quer esclarecer quem o denunciou e provocou sua expulsão da universidade forçando-o ao exílio.

A fluidez narrativa desse primeiro plano temporal se interrompe para dar voz ao próprio José María Heredia, a começo do século XIX, quando Cuba pertencia ao domínio espanhol. Neste nível, o estilo distanciado e impessoal do narrador muda para a primeira pessoa, e o narrador se inclui na história, identificado com o nome de José Maria Heredia. Esta última entrada adquire assim características de uma narração autobiográfica. Finalmente, um terceiro plano surge: a narração em terceira pessoa dos últimos dias de José de Jesús de Heredia, filho do poeta e seu último executor, pertencente às $\operatorname{logias}^{2}$ maçónicas cubanas, cuja história, transcorre a inícios do século $\mathrm{XX}$. Além dos relatos biográficos dos três personagens centrais também encontramos referências a aspectos políticos, sociais e literários da História de Cuba.

José María Hereida (1803-1839) é considerado pelos críticos ${ }^{3}$ o primeiro poeta romântico da língua espanhola, também o primeiro grande poeta cubano condenado a morrer no exílio por ter expressado um sentimento patriótico em oposição ao regime espanhol. Ainda muito jovem vinculou-se aos movimentos independentistas sendo acusado, em 1823, de participar na conspiração de los soles y rayos de Bolívar, reprimida violentamente pelo Geral Vives. Diante da ameaça de prisão parte clandestinamente para o exílio em Nova York onde escreveu seu famoso Ode ao Niágara e publicou seu primeiro livro de poemas. Anos mais tarde vai morar no México, aí morre vítima da tuberculose, com apenas 36 anos. No exílio escreveu uma parte muito importante da sua poesia ressaltando a imagem de Cuba, a nostalgia por Cuba e a sua visão da necessidade da liberdade em Cuba, temas fundamentais de sua obra. Em 1825 publicou Hino do desterrado, um dos poemas mais conhecidos de Heredia onde descreve as emoções que desperta no poeta a imagem da colina Pan de Matanzas ao passar perto de Cuba (sem poder visitar a ilha) na travessia de Nova York ao México:

\footnotetext{
"Terra!" Exclamam: olhamos ansiosos

Os confins do sereno horizonte,

E longe descobre-se um monte

O reconheço ... Olhos tristes, chorar!

É o Pan... em sua encosta respira

$\mathrm{O}$ amigo mais fino e constante,

Minhas amigas preciosas, minha amante ...
}

\footnotetext{
${ }^{2}$ Em espanhol: nome do lugar onde os maçons celebram as assembleias.

${ }^{3}$ Chacón y Calvo, Andrés Bello, Alberto Lista, Enrique Piñeyro, Antonio Cánovas del Castillo, Domingo del Monte, Marcelino Menéndez y Pelayo, Cintio Vitier, entre outros autores.
} 


\section{SEMINÁRIO DE PESQUISA EM CIÊNCIAS HUMANAS - SEPECH \\ Humanidades, Estado e desafios didático-científicos \\ Londrina, 27 a 29 de julho de 2016}

O que tesouro de amor tenho lá! ${ }^{4}$

(HEREDIA, 2015, p. 195) [tradução minha].

A dor do exílio, as ideias independentistas, a força da natureza, o amor romântico, a penúria social são, entre outras, as principais fontes de inspiração de Heredia com as que inaugura o imaginário de sua pátria. Em "O mar e os regressos", primeira parte de $O$ romance de minha vida, diversos aspectos da vida colonial cubana são apresentados ao leitor desde a aproximação introspectiva da autobiografia de José María Hereida. La Habana, epicentro da história, é descrita pelo poeta ressaltando, especialmente, o lado sórdido da cidade: a prostituição, a escravatura, a crescente pobreza. A presença da prostituição denuncia a situação das escravas negras fleteras $^{5}$ que trabalhavam nessa situação para receber uma pequena quantia que lhes permitiria a compra de sua alforria: "[...] naquela noite aprendi como a indústria da prostituição prosperou na ilha mais do que na fabricação de açúcar, e como o negócio era especialmente útil para a escravas fleteras [...] pois essas infelizes tinham como meta a compra de sua liberdade" (PADURA, 2002, p. 31, 32) [tradução minha]. Segundo Hereida, o caos imperante em La Habana colonial deve-se ao sistema escravista e a todas suas mazelas, revelando também o temor entre os poderosos membros da burguesia cubana diante de uma possível sublevação dos escravos como já tinha acontecido nas ilhas vizinhas:

Os negros febris pelo toque rústico dos atabaques e, provavelmente, afogados em aguardente, dançavam como possessos [...] Essa dança, que naquele mesmo dia e em pequena escala era reproduzida em todas as aldeias da ilha, em cada usina de açúcar e cada plantação de café, foi como um aviso do que não se podia permitir: porque o infame comércio de escravos tinha feito dos negros e mulatos a maior parte da população do país, e essa dança dos tambores demostrava a força poderosa de homens que, de encontrar um líder, poderiam reverter o destino da ilha como há alguns anos atrás tinha acontecido na próspera Saint Domingue $^{7}$ (PADURA, 2002, p. 28) [tradução minha].

\footnotetext{
4 "!Tierra!" claman: Anciosos miramos

al confín del sereno horizonte,

Y a lo lejos descúbrese un monte...

Le conozco... ¡Ojos tristes, llorad!

Es el Pan... en su falda respiran

El amigo más fino y constante,

Mis amigas preciosas, mi amante...

¡que tesoro de amor tengo allí! (HEREDIA, 2015, p. 195).

${ }^{5}$ Em Cuba, prostituta que percorre as ruas em busca de clientes.

6 "Esa noche aprendí cómo la industria de la prostitución prosperaba en la isla más que la fabricación de azúcar, y cómo el negocio era especialmente provechoso en la modalidad de las esclavas fleteras [...] pues aquellas infelices tenían como norte comprar su libertad" (PADURA, 2002, p. 31, 32).

${ }^{7}$ Los negros afiebrados por el toque rústico de los tambores, y seguramente anegados en aguardiente, bailaban como posesos [...] Aquel baile, que ese mismo día y en pequeña escala se reproducía en cada pueblo de la isla, en cada ingenio azucarero y en cada cafetal, era como una advertencia de lo que no se podía permitir: porque la infamante trata de esclavos había convertido a los negros y mulatos en la mayoría de la población del país, y aquella danza de los tambores demostraba la fuerza pujante de unos
} 


\section{SEMINÁRIO DE PESQUISA EM CIÊNCIAS HUMANAS - SEPECH \\ Humanidades, Estado e desafios didático-científicos \\ Londrina, 27 a 29 de julho de 2016}

$\mathrm{Na}$ autobiografia, o olhar de Hereida sobre sua época é introspectivo, panorâmico, crítico. A visão da sociedade cubana e dos países onde viveu o exílio também representam um exame de se mesmo, que o poeta recria nas evocações de sua memória. "Nesse sentido, o ambiente é tão importante quanto o personagem, porque o indivíduo é apenas um reflexo do que o rodeia. [...] Heredia, tal como apresentado por Leonardo Padura, é uma miragem do seu tempo, uma imagem que ele está recriando em cada linha de suas memórias"8 (BEHAR. 2007, p. 25) [tradução minha].

Se o olhar de José María Heredia é introspectivo, o de seu filho José de Jesús é retrospectivo. Oitenta anos depois da morte de seu pai, idoso e pobre, enfrenta o dilema moral do que fazer com os manuscritos herdados para não macular a imagem do insigne poeta. Uma primeira opção seria esconder esses velhos papeis na Câmara Secreta da logia maçônica, outra, vender os documentos resolvendo as suas dificuldades econômicas. Porém, vender os manuscritos significaria dessacralizar a imagem de seu pai pois mudaria totalmente a visão da história e a de seus contemporâneos. Também cogita a possibilidade de destruir os manuscritos, o que evitaria humilhações aos descendentes e amigos próximos, ao ocultar segredos importantes sobre a trajetória amorosa, política e literária de José María Heredia. Ao resolver o destino dos manuscritos, José de Jesús alterará o percurso da história quando são entregues a Ricardo Junco, provável bisneto de Lola Junco, (amante de José María), quem os queima, como explicado no final do romance, eliminando assim parte da vida de seu pai e criando, desta forma, uma nova versão da História cubana.

O último nível narrativo, que dá início ao romance, como já dito, acontece no século XX com o regresso de Fernando Terry à ilha para buscar a autobiografia de José María Hereida e reencontrar "Los Socarrones", os amigos de sua época de estudante que o acompanharam na procura dos manuscritos, e com os que tentará esclarecer quem o denunciou e provocou sua expulsão da universidade forçando-o ao exílio.. A visão de Terry sobre a vida em La Habana é fragmentada, distante, evocativa, é o olhar do exiliado que ao voltar a seu lugar de origem descobre com surpresa o passo do tempo, pois os lugares e as pessoas não são mais os mesmos: "[...] beberia o café suave e doce que costumavam coar na velha cafetaria que agora, com ardor infinito, descobriu que apenas existia em sua persistente memória [...] a cafetaria de Las Vegas e seu balcão de mogno polido haviam desaparecido, assim como muitas outras coisas na vida"9 (PADURA, 2002, p. 16) [tradução minha].

O fio condutor em $O$ romance de minha vida é a experiência do exílio, comum aos três personagens da história. José de Jesús viveu toda sua vida em Cuba mas experimentou uma espécie de exílio interior ao ficar isolado dentro do universo da

hombres que, de hallar un líder, podrían revertir el destino de la isla, como unos años atrás había sucedido en la próspera Saint Domingue (PADURA, 2002, p. 28).

\footnotetext{
8 "En ese sentido, el entorno es tan importante como el personaje, porque el individuo es sólo un reflejo de aquello que le rodea. De hecho, Heredia, como lo presenta Leonardo Padura, es un espejismo de su tiempo, una imagen que él mismo va re-creando en cada renglón de sus memorias" (BEHAR. 2007, p. 25).

9 “[...] bebería el café leve y dulzón que solían colar en la vieja cafetería que ahora, con ardor infinito, descubrió que ya sólo existía en su persistente memoria y en alguna literatura de la noche habanera: la cafetería de Las Vegas y su invencible mostrador de caoba pulida se había esfumado, como tantas otras cosas de la vida" (PADURA, 2002, p. 16).
} 


\section{SEMINÁRIO DE PESQUISA EM CIÊNCIAS HUMANAS - SEPECH \\ Humanidades, Estado e desafios didático-científicos \\ Londrina, 27 a 29 de julho de 2016}

maçonaria ao que dedicou parte de sua existência. Já Hereida e Terry, mesmo pertencendo a épocas diferentes, experimentam a dor e a nostalgia do desterro que parecera irmanar suas vidas ao começo e final do romance. "E não é apenas o presente que olha nostálgico para o passado, mas também o passado que olha sem esperança para o futuro ${ }^{10 "}$ (BEHAR, 2007, p. 28). Nesse jogo de perspectivas, o nexo mais profundo entre os dois personagens é o regresso à pátria e é durante suas respectivas viagens de regresso quando os dois poetas se encontram. Sentado no miramar da Havana, Terry vê passar um veleiro em que um homem se inclina sobre o, olhando-o fixamente:

Aquele desconhecido que o observa de forma penetrante, o alarmou e fê-lo sentir, como uma rêmora capaz de voar sobre o tempo, a dor que deveu de afligir José María Heredia naquela manhã, provavelmente fria, de 16 de Janeiro de 1837, quando ele viu, desde o brigue que o devolvia para o exílio depois de uma dilacerante visita à ilha, como as ondas se afastavam em busca precisamente daqueles recifes, a última curva da terra cubana que o poeta nunca mais veria ${ }^{11}$ (PADURA, 2002, p. 17) [tradução minha].

Ao final da autobiografia, o passado se reencontra com o presente assim como realidade se dissolve na ficção, no momento em que José María Hereida descreve sua partida definitiva da ilha, e lembra do momento quando se reclinou sobre o corrimão da embarcação e descobriu um homem que segue com olhar atento o passo do navio:

Nossos olhares se cruzaram, e recebi a dor recôndita que carregavam aqueles olhos, uma tristeza estranhamente igual à minha, capaz de atravessar por cima das ondas e do tempo para forjar uma misteriosa harmonia que desde então tira o meu sonho, pois sei que fomos algo mais que dois homens se olhando sobre as ondas ${ }^{12}$ (PADURA, 2002, p. 332) [tradução minha].

Num jogo de revelações e segredos, os três níveis narrativos de $O$ romance de minha vida são construídos, como já vimos, na mistura de personagens imaginários com personagens reais, na experimentação com a identidade do narrador-autor-personagem, ao usar eventos históricos reais como base para criar a narrativa a partir do uso do discurso ficcional, que não teria presunção de verdade, com o discurso autobiográfico

\footnotetext{
10 "Y no se trata solamente del presente que mira nostálgico al pasado, sino también del pasado que mira desesperanzado hacia futuro.

11 Aquel desconocido, que lo observaba con tal escrutadora insistencia, alarmó a Fernando y le hizo sentir, como una rémora capaz de volar sobre el tiempo, el dolor que debió de embargar José María Heredia en aquella mañana, seguramente fría, del 16 de enero de 1837, cuando vio, desde el bergantín que lo devolvía al exilio luego de una lacerante visita a la isla, cómo las olas se alejaban en busca precisamente de aquellos arrecifes, el último recodo de una tierra cubana que el poeta ya nunca volvería a ver (PADURA, 2002, p. 17).

${ }^{12}$ Nuestras miradas se sostuvieron, y recibí el pesar recóndito que cargaban aquellos ojos, una tristeza extrañamente gemela a la mía, capaz de cruzar por encima de las olas y el tiempo para forjar una misteriosa armonía que desde entonces me desvela, pues sé que fuimos algo más que dos hombres mirándose sobre las olas (PADURA, 2002, p. 332).
} 


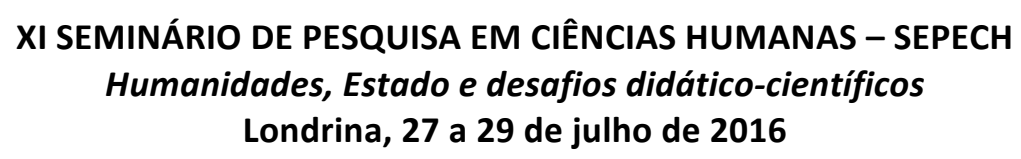

em que sim existiria essa presunção. Dessa forma, dissolvem-se as fronteiras entre literatura e vida real, recurso com o qual se desestabiliza o estatuto ficcional do literário, pois, como afirma Juan José Saer: “[...] a verdade não é necessariamente o contrário da ficção ${ }^{13 "}$ (SAER, 1997, p. 9) [tradução minha], e mesmo que "a literatura sempre seja inatual, dize em outro lugar, fora de hora, a verdadeira história ${ }^{14, " ~(P I G L I A, 1986, ~ p . ~ 78) ~}$ [tradução minha]. Cabe ao leitor decidir em qual desses dois lugares quer permanecer.

\section{REFERÊNCIAS}

BEHAR, Sonia. "Perspectivismo y ficción en La novela de mi vida: la historia como versión de sí misma". In: JUAN-NAVARRO, Santiago; TORRES-POU, Joan. Memoria histórica, Género e Interdisciplinariedad: Los Estudios Culturales Hispánicos en el siglo XXI. Madrid: Biblioteca Nueva, 2007, p. 23-30.

GUTIÉRREZ, Rafael. "Formas híbridas na narrativa latino-americana contemporânea". In: Revista Landa, v. 3, n. p. 94-115, 2015.

HEREDIA, José María. "Himno del desterrado". In: ORTEGA, Julio et all. Letras de Hispanoamérica. Nueva antología de la literatura de las Américas. Boston, Massachusetts: Vista Higher Learning, 2014.

OLMOS, Ana Cecilia. "Transgredir o gênero: políticas da escritura na literatura hispano-americana atual". Revista Estudos de Literatura Brasileira Contemporânea. n. 38, Brasília: julho/dezembro, 2011.

PADURA FUENTES, Leonardo. La novela de mi vida. Barcelona: Tusquets Editores, 2002 (Col. Andanzas).

José María Heredia: la patria y la vida. La Habana: Ediciones Unión, 2003.

PIGLIA, Ricardo. Crítica y ficción.

SAER, Juan José. El concepto de ficción. Buenos Aires: Seix Barral, 1997.

\footnotetext{
13 “[...] la verdad no es necesariamente lo contrario de la ficción” (SAER, 1997, p. 9).

${ }^{14}$ La literatura siempre es inactual, dice en otro lugar, a destiempo, la verdadera historia (PIGLIA, 1986, p. 78).
} 